Author post-print (ie final draft post-refereeing

Published version

Vari Drennan Sarah Andrews Rajinder Sidhu Richard Peacock

Attracting and retaining nurses in primary care British journal of community nursing. , 2006,

Vol.11(6), p.242-246

\title{
Attracting and Retaining Nurses into Primary Care
}

Vari Drennan, Sarah Andrews, Rajinder Sidhu \& Richard Peacock

Authors

Dr Vari Drennan, Director The Primary Care Nursing Research Unit, UCL \& KCL, London

Professor Sarah Andrews, Director of Nursing Camden PCT

Rajinder Sidhu, Researcher, Institute of Psychiatry, KCL

Richard Peacock, Clinical Librarian Middlesex University

Contact email address 2017

v.drennan@sgul.kingston.ac.uk 


\section{Abstract}

There is increasing demand for nurses to work in primary care. This is driven in part by the need to retain current levels but also by the modernisation plans for primary care services, which require new roles for nurses, new ways of working and more nurses in primary care settings. While campaigns for increased recruitment of hospital nurses and doctors has been largely successful in recent years, primary care has still to see the impact. This paper reports on a Department of Health (England) funded project that aimed to identify strategies and exemplars to assist Primary Care Trusts (PCTs) and the Workforce Development Confederations (WDCs) in Strategic Health Authorities in attracting and retaining nurses to primary care at registered nurse level. It reports on the range of initiatives identified, the perceived benefits and challenges. It concludes by proposing a strategic model for planning for the recruitment and retention of primary care nurses. 


\section{Key words}

Nursing workforce, recruitment and retention, primary care, district nursing

\section{Key Points}

- There is increasing demand for nurses to work in primary care.

- There is regional variation England on recruitment and retention issues in Primary care nursing, particularly district nursing

- A systematic literature and grey literature search revealed a small number of initiatives and no longitudinal evaluations of impact. However a scoping exercise revealed a number of different types of initiatives specifically targeted at improving the recruitment, retention and career development of registered nurses into primary care.

- A model of recruitment and retention, that addresses all sources of registered nurses as well as career development through periods of transition , can aid strategic planning. 


\section{Introduction}

There is increasing demand for nurses to work in primary care. The modernisation and expansion of primary care services has been a fundamental element of improvement plans for the NHS across the UK. In England it has recently been reemphasised (Department of Health 2006). The delivery of increased and different levels of services in primary care has been underpinned both by new contractual arrangements and also by a strong focus on the recruitment and retention of general practitioners (Department of Health 2004a). At the same time the Department of Health in England has highlighted the need for a more flexible, generalist nursing workforce to support the modernisation agenda for primary care services (Department of Health 2002a). The plans for the NHS, including the new GMS and PMS contracts, the chronic disease management/long term conditions programmes, and the public health agenda require new roles for nurses, new ways of working and more nurses in primary care settings. This paper reports on a Department of Health (England) funded project. It aimed to identify strategies and exemplars to assist Primary Care Trusts (PCTs) and the Workforce Development Confederations (WDCs)in Strategic Health Authorities in attracting and retaining nurses to primary care at registered nurse level.

\section{The Project Activities}

This project focused on the issues of providing flexible entry and career progression routes for registered nurses into primary care to complement the human resource and Improving Working Lives frameworks provided by the Department of Health (DoH 2002b, DoH undated). An expert advisory group of primary care practitioners, educators and commissioners drawn from across England advised and informed the progress of the project. A number of activities were undertaken to identify strategies and exemplars. These included: 
- A detailed profiling and modelling of the primary care workforce to identify key issues in recruitment and retention (Drennan et al 2004a)

- A systematic search of published literature and unpublished literature on recruitment and retention issues and initiatives into primary care nursing into primary care (Sidhu et al 2004). This included an electronic scoping exercise on both web based information and though electronic requests to 60 primary care leads in higher education institutes, 260 lead nurses in PCTs and 28 lead managers for primary care in WDCs

- Participation in 8 Strategic Health Authority workshops designed to consider the local progress on the national guidance for developing primary care nursing (DoH 2002a)

- A national seminar to present the findings and test emerging evidence and strategies to primary care practitioners, commissioners, and academics

\section{Current issues in recruitment and retention}

In 2004 there were 58,551 wte qualified nurses and health visitors working in primary care settings (including general practice), approximately $18.5 \%$ of the total nursing, midwifery and health visiting workforce in NHS England. This is a number that has been growing over the past decade but at different rates for the different groups of nurses (Figure 1). 


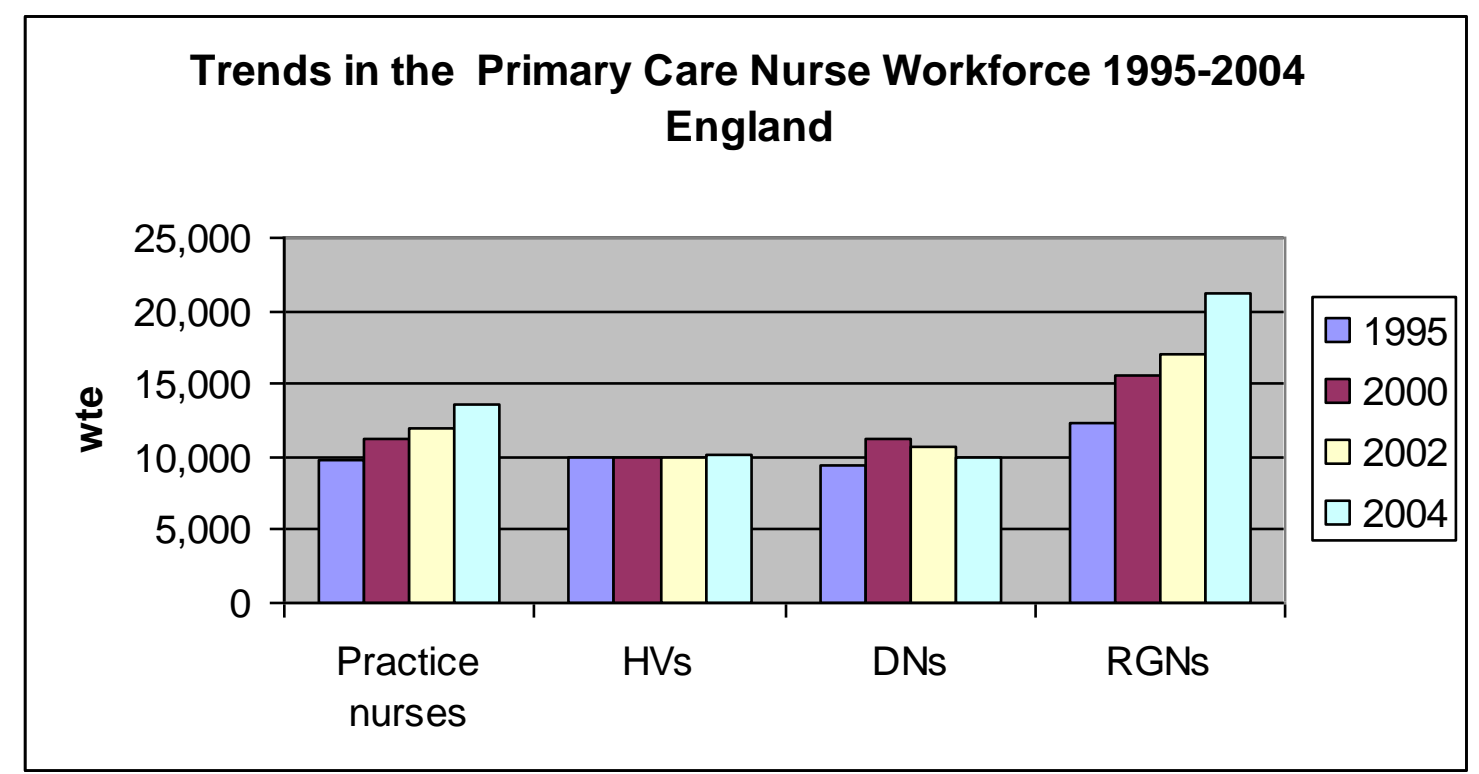

Figure I Sources Department of Health England Non Medical Workforce Census 1995 -2004 Department of Health England General Practitioner Census 1995 -2004

It is a workforce that is predominately female, including only $2.5 \%$ male nurses and tends to have an older age profile than the acute sector nursing workforce (Drennan et al 2004a). The project identified that there were regional variations across England in issues of current recruitment and retention. The project used geographical information systems to map Department of Health (England) workforce data. Map 1 illustrates the regional variation in qualified district nurse posts per 10,000 population ranging from 0.9 - 5.7 wte per 10,000 population. Map 2 illustrates the regional variation in district nurse posts vacant for over 3 months ranging from none in some areas to over $9 \%$ in others. The project identified two main drivers behind the demand for registered nurses in primary care. The first is expansion thorough the NHS modernisation agenda. The second driving force is the maintenance of current levels of service in the face of recruitment and retention problems in the primary care nursing and general practice workforce. 
Map 1

Number of District Nurses (wrte) per 10,000 Poulation (SHA)

Enzland 2002

$\stackrel{N}{N}$

2.7

$0.9-2.6$

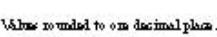

Datimas: 092.3

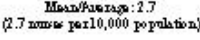

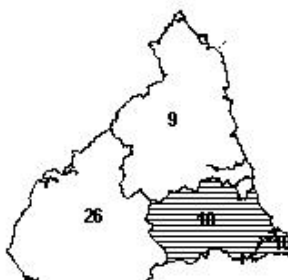

26

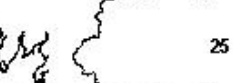

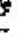

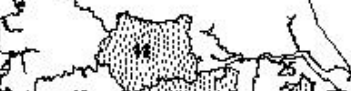

A 120

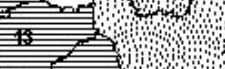

党
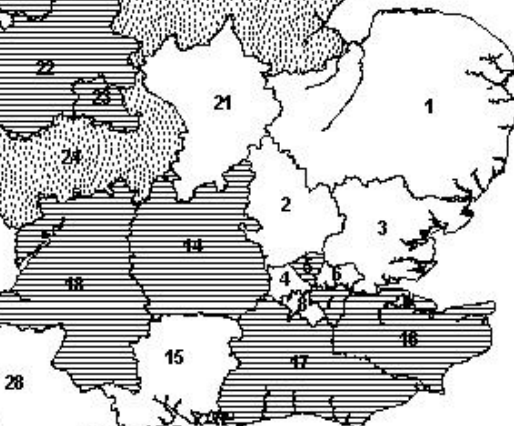

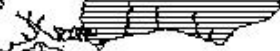
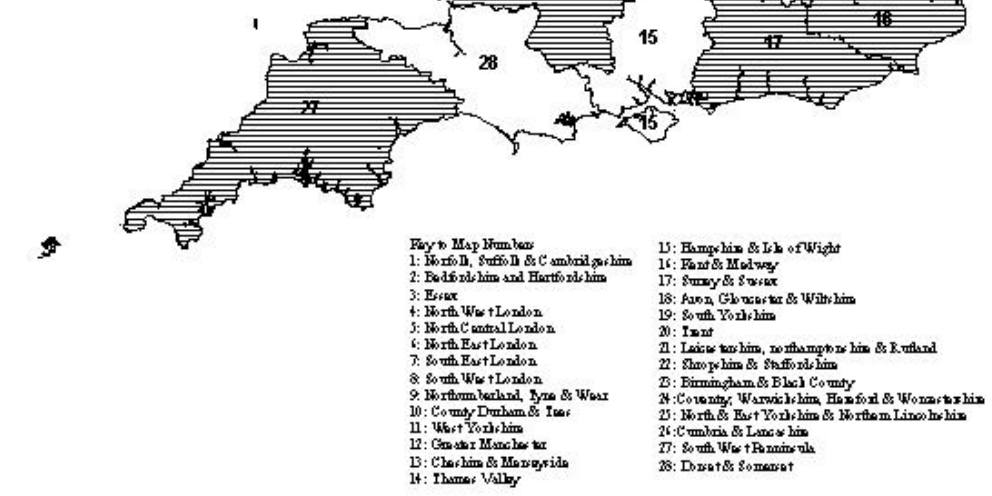

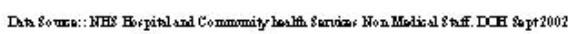


Map 2

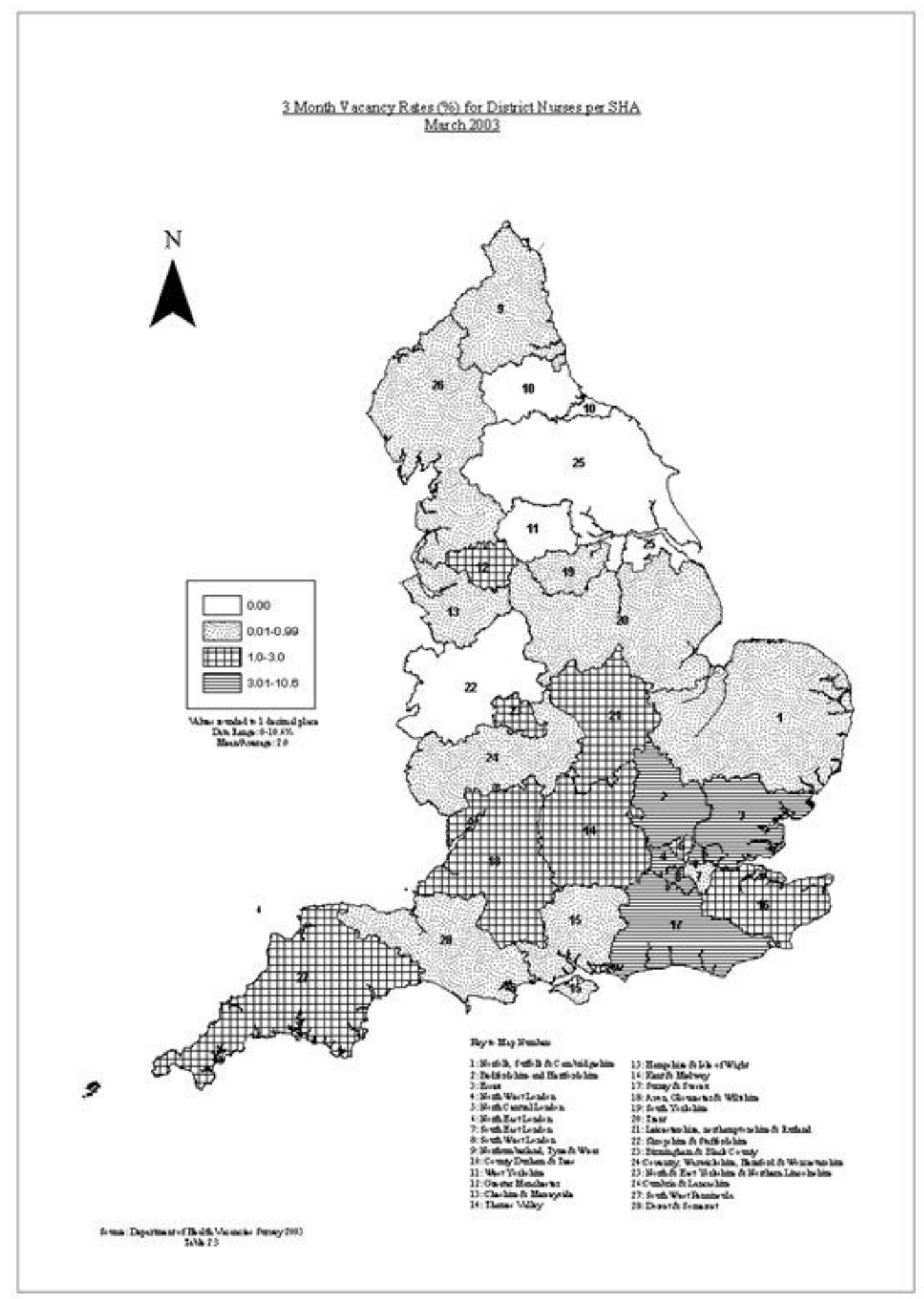




\section{The literature on addressing primary care nursing workforce issues}

The systematic literature search found eleven published papers and two unpublished reports on initiatives to address some aspect of recruiting and retaining registered nurses into primary care. Most of this lliterature was descriptive rather than evaluative. Six were very brief descriptions of initiatives e.g. a primary care nursing strategy (Ali 2001), often written by journalists but without any basic details like numbers of nurses. Four papers concerned career pathways and training in practice nursing (Drennan and Catterson 1997, Bishops and Jones 2000, Stark et al 2001, Crawford 2001), two were concerned with the introduction of different types of qualified nurses into services (Wright 2002, Hunt 2003). Four papers described human resource management type strategies focused on primary care nurses. These included a flexible retirement project (Torrance 2003), a tailored primary care clinical induction programme (Donovan 2003 ), and competency frameworks to clarify career progression routes (Yole and Barrett 2003, Webster et al 2003). Another article described the establishment of a rotational placement scheme in all primary care nursing services for secondary care nurses (Edwards 2000). Lastly the establishment of newly qualified nurse posts with preceptorship scheme in primary care was described(Crouch 2003). Only four of these papers reported systematic methods of evaluation. All of them described on small-scale initiatives with very small numbers reported to be perceived as valuable. None of them reported on longer-term evidence of impact, or compared to other types of initiatives or provided an economic evaluation. A recent electronic repeat of the literature search revealed only one more published paper describing a rotational placement model in district nursing services and practice nursing for secondary care nurses( Bellot and Baker 2005). There were no further publications reporting evaluations of schemes or innovations. 
Although little literature was found on the recruitment and retention of nurses to primary care in the UK, the project identified some key issues that are significant for those addressing workforce development in primary care. There is some evidence that, on registration, nurses chose to work in areas as a direct result of positive clinical experiences during training. UK research of nurse student cohorts indicates that primary care has to date not been viewed positively as an occupational option (Happell 1999, Robinson et al 2000). Human resource studies on recruitment demonstrate that post holders working with students can be very effective in recruiting those students into that organisation. Despite this, there are very few opportunities for student nurses to learn clinical skills in primary care (David Cottam Consultancy 1996) rather than just observe, although a sixth of all nurses employed in the NHS work in primary care.

\section{Addressing the current and projected demands for nurses in primary care}

The project found that few PCTs and WDCs were reporting strategic approaches to projecting demand for nurses in primary care in line with local delivery plans although some had work in progress (e.g. Campbell 2004,). Through the project activities, providers and commissioners of primary care services and education reported that they had developed initiatives to address a primary care nursing workforce shortfall in response to two key issues:

- Entry routes into primary care nursing were complex, confusing and convoluted,

- There was a mismatch between service needs and current specialist practice education provision. Further to this the associated finances were too rigid for changing service demands.

The electronic scoping exercise revealed a small number of initiatives across

England which specifically addressing the recruitment and retention issues for 
nursing in primary care. Six types of initiatives were identified that targeted qualified nurses (Table 1) both at different stages of their careers e.g. newly qualified registered nurses or for particular parts of the workforce e.g. practice nursing.

\begin{tabular}{|l|c|}
\hline Initiative & Number \\
\hline $\begin{array}{l}\text { Induction courses and training posts for registered nurses } \\
\text { entering practice nursing some linked to degree modules }\end{array}$ & 7 current \\
\hline $\begin{array}{l}\text { Rotational training posts, providing clinical experience in } \\
\text { more than one area of primary care nursing (sometimes } \\
\text { into the acute sector) and linked to education pathways }\end{array}$ & 11 current \\
\hline $\begin{array}{l}\text { Supported work based learning programmes, clinical } \\
\text { induction programmes, formal preceptor schemes for } \\
\text { registered nurses new to primary care and nurses returning } \\
\text { to practice }\end{array}$ & 10 current \\
\hline $\begin{array}{l}\text { Return to primary care nursing courses and associated } \\
\text { bursary schemes }\end{array}$ & 2 planned \\
\hline $\begin{array}{l}\text { Work based education programmes to degree level } \\
\text { education for registered nurses working in primary care }\end{array}$ & 2 planned \\
\hline $\begin{array}{l}\text { Other recruitment and retention initiatives across primary } \\
\text { care nursing e.g. marketing campaigns, flexible retirement } \\
\text { projects, primary care health care assistant development } \\
\text { programmes }\end{array}$ & 2 planned \\
\hline
\end{tabular}

Table 1: Initiatives to support the recruitment of registered nurses identified across England in 2004

Providers and commissioners of primary care services identified two further issues that hindered progress with recruitment and retention of primary care nurses:

- Pre-registration curriculum and clinical learning experiences for nurses in primary care were too limited,

- Few clinical learning placements were available in general practice,

The scoping exercise revealed two further types of initiative specifically at student nurse experience

\begin{tabular}{|l|c|}
\hline Initiative & Number \\
\hline Provision of increased levels of clinical placements with & 11 current \\
skills learning for nursing students in the final year of their & 6 planned \\
\hline
\end{tabular}




\begin{tabular}{|l|c|}
\hline studies, including in general practice & \\
\hline Improved clinical placements for nursing students in & 6 current \\
primary care through a primary care based practice & 4 planned \\
educator & \\
\hline
\end{tabular}

Table 2 initiatives to support the future recruitment of registered nurses in primary care in 2004

Many of the initiatives reported were still in the planning stage and informants were keen to learn from others experiences. While the initiatives reported were spread across England, it was noticeable that the large urban conurbations and particularly London produced the greater density.

While providers and commissioners were able to report very positive opinions about their initiatives to address these issues, they also shared some common challenges:

- Finance for some initiatives, such as rotational training posts in primary care for registered nurses, was not mainstream and therefore continuation uncertain.

- PCT and GP employers of primary care nurses often had different perceptions of priorities and human resource management practices that impacted on longer-term strategies for attracting and retaining increased numbers of nurses to primary care.

- There was a danger of overloading some groups of experienced nurses in community nursing services with responsibilities for mentoring, training and preceptorship.

The development of new types of services and changes in the GMS contracts are creating increased demand for registered nurses in primary care from multiple competing employers. There was a perceived need and demand for shared templates for clinical induction programmes, job descriptions and competency frameworks, and career progression to support general practices and PCTs. as employers. Informants pointed to the significance of employer reputation in any 
primary care area where there are multiple competing employers of nurses, particularly at times of higher demand for nurses.

\section{A Model for Attracting and Retaining Registered Nurses in Primary Care}

Having identified the range of issues and the types of initiatives being explored in response to current and projected demand, the project team returned to consider the gap in strategic planning. Using an expert advisory group from general practice, PCTs, Universities and WDCs a framework was developed to help those managers responsible for commissioning and providing services and education think more strategically about recruitment and retention of nurses in primary care (figure 2). It was designed to take cognisance of the different pools of nurses who could potentially enter the primary care workforce at the same time as considering the career development of those already working there, or at points of life transition. This framework forms the spine of a guide to attracting and retaining nurses in primary care, which was produced and shared with managers in participating PCTs, WDCs and Universities (Drennan et al 2004b) 
Figure 2

\section{A Model for Attracting and Retaining Registered Nurses in Primary Care}

Pre-Registration Nurses

- Recruit from a pool of support workers working in primary and community settings

- Increase learners knowledge of the range of nursing work in primary care

- Create clinical skills learning opportunities in primary care services rather than just observation

- Market primary care job opportunities, clinical induction programmes and flexible working through primary care nurse mentors and prequalification opportunities

- Utilise a wide range of clinical placements including general practice

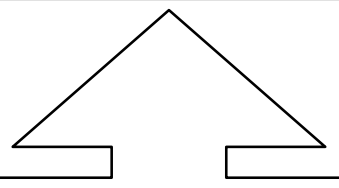

Newly Qualified Nurses \& New To Primary Care Nurses

- Market job opportunities and flexible working through universities

- Establish primary care registered nurse training posts

- Support first months in post through preceptors and clinical induction programmes

- Increase nurses knowledge of the range of nursing work in primary care including developing rotations

- Provide opportunities to work/shadow in different primary care services

- Link nurses learning activities to accredited educational programmes

- Increase knowledge of caree progression routes, including specialist and advanced practice

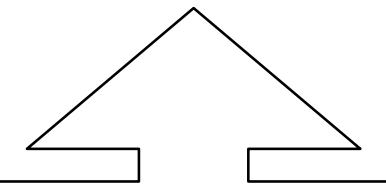

Experienced Registered Nurses in Primary Care

(e.g. long experience as a 'staff nurse' in community nursing)

- Market job opportunities and flexible working

- Increase nurses knowledge of the range of nursing work in primary care and develop rotational posts

- Provide opportunities to work/shadow in different primary care services

- Provide clinical induction programmes

- Address continuing professional development needs that link to career progression and educational portfolios

- $\quad$ Link learning to accredited educational programmes

- Recruit to "bank", locum schemes, NHS Professionals

- Identify career development and progression routes, including specialist and advanced practice and consultant practice

\section{Registered Nurses At Life \\ Transition Points}

(e.g. Leaving or Have Left Primary Care for Parenthood Dependent Support or

$$
\text { Retirement) }
$$

- Market different types of job opportunities, flexible working and flexible retirement options

- Set up "keep in touch" schemes while they are on career breaks

- Increase nurses knowledge of the range of nursing work in primary care

- Recruit to "bank", locum schemes, NHS Professionals

- Help address continuing professional development needs while on career breaks

- Establish Return to Primary Care Courses/Opportunities for those out of nursing work for more than five years

- Establish clinical induction and supported entry routes for those returning to work after shorter breaks 


\section{Conclusion}

It is apparent that the drivers to address issues of recruitment and retention in primary care vary between different geographical areas and health economies. This project identified a range of creative innovatory schemes but a lack of publicly available material to both replicate them or learn form them. It also identified the lack of longitudinal analysis or any evaluation beyond perceived benefits. Given that all government in the UK continue to emphasis the role of primary care, the lack of detailed analysis and strategic planning remains all the more surprising. It is a gap that should be addressed at PCT, WDC and Department of health levels. 


\section{References}

Ali.S Nursing Strategy for Heart of Birmingham PCG. Primary Health Care, 2001.

Bellot a and Baker L 2005 Bishop T and Jones. J Working together to support new practice nurses. A practice nurse apprenticeship scheme.2000.

Campbell P 2004 A Report on Primary Care Nursing in Shropshire and Staffordshire 2003-2004 Shropshire and Staffordshire Strategic Health Authority and Workforce Development Confederation

Couch.D (2003) Straight to the Heart. Nursing Times 99 (15), 2003.

Crawford M. (2001) Initiative: Introduction to Nursing in General Practice: Professional Development 9 February 2001. www.reedbussiness.com

Department of Health.England (2006) Our Health, Our Care, Our Say : A new Direction for Primary Care Services The Stationary Office Cm 6737

Department of Health 2002a Liberating the Talents: the Nursing: helping PCTs and nurses to deliver the NHS Plan. Department of Health, London.

Department of Health England 2002 b Primary Care Work Force Planning Framework. ht http://www.doh.gov.uk/pricare/pcwpf.htm accessed on 15/11/03

Department of Health (undated) Strategies and Polices for Human Resources in the NHS http://www.dh.gov.uk/PolicyAndGuidance/HumanResourcesAndTraining/fs/en accessed 20/4/04

Department of Health (2004a) Chief Executive's Report to the NHS: December 2004. London, Department of Health

Donovan $\mathrm{P}$ (2003) A clinical induction programme to primary care nursing . Camden PCT \& Islington PCT unpublished report

Drennan D and Catterson. J 1998 Evaluation of the Pilot for Creating Career Pathways into Primary Care Nursing. Camden \& Islington Health Authority/University College London Unpublished Report

Drennan v, Andrews S, Sidhu R and Peacock R 2004a Final Report Flexible Entry to Primary Care Nursing Project: Improving Recruitment and Retention in Primary Care. The Primary Care Nursing Research Unit PDF file available at http://www.ucl.ac.uk/pcps/research/pcnru/publications.htm

Drennan v, Andrews S, and Sidhu R 2004b A Guide to Improving Recruitment and Retention in Primary Care. The Primary Care Nursing Research Unit. PDF file available at http://www.ucl.ac.uk/pcps/research/pcnru/publications.htm

Edwards N. 2002. Trading Places. Health Services Journal, 19 June p 20

Happell. B 1999 When I grow up I want to be a...? Where undergraduate student nurses want to work after graduation. Journal of Advanced Nursing 29 (29),. 
Robinson S Marsland L, Murrells T et al 2000 Project One: Careers of Registered General Nurses at 8 years post qualifying. Unpublished report. Nursing Research Unit. Kings College London

Sidhu R, Peacock R, Drennan V (2004)The Recruitment and Retention of Registered Nurses into Primary Care in England. A bibliography 1991-2004 The Primary Care Nursing Research Unit. PDF file available at http://www.ucl.ac.uk/pcps/research/pcnru/publications.htm

Stark, S Warne T, and Street C. 2001.Practice Nursing: An Evaluation of a Training Practice Initiative. Nurse Education Today,

Webster B and Akufo-Tettah. M 2003.Practice Nursing: A Structure for Career Progression. Primary Health Care 13 (1),

Wright C (2002) In for the Skill Health Service Journal 18 July 2002 p 26-27 